\title{
Dehydroepiandrosterone Measurement
}

National Cancer Institute

\section{Source}

National Cancer Institute. Dehydroepiandrosterone Measurement. NCI Thesaurus. Code C74852.

The determination of the amount of dehydroepiandrosterone hormone present in a sample. 